\title{
Considerations for Dielectric Properties Measurements of Oil Immersed Pressboard
}

\author{
Fari Pratomosiwi ${ }^{1}$, Norasage Pattanadech ${ }^{1}$, B. Wieser ${ }^{1}$, G. Pukel ${ }^{2}$, M. Stössl ${ }^{2}$, Michael Muhr ${ }^{1}$ \\ ${ }^{1}$ Institute of High Voltage Engineering \& System Management, \\ Technische Universität Graz, Inffeldgasse18, 8010 Graz, Austria \\ ${ }^{2}$ Siemens Transformer Austria GmbH \&Co KG, Elingasse 3, 8160 Weiz, Austria
}

\begin{abstract}
Dielectric properties including relative permittivity, dielectric dissipation factor (DDF) and dc resistivity has been used widely as a design parameter of insulation system. In measuring dielectric properties of oil immersed material (OIM), we have to make some adaptations from IEC 60093 and IEC 60250.This paper is focused on dielectric properties measurement of oil immersed pressboard (OIP) i.e. related to the effect of live electrode corner shape, the effect of electrode's weight, and the applied the electric field stress and temperature.In this experiment, the solid and liquid dielectric wereoil immersed transformer board type B 3.1A and operated under mineral oil bath, Nynas Nytro 4000x. We concluded that, round-cornered electrode yields steep electric field enhancement at the oil side. This phenomena makes it easier to generate oil discharge in the wedgewhen compared to sharp-cornered electrode. For measuring dielectric properties at high voltage level, this phenomenon should take into account. It was also found that electrode with pressure higher than $1.9 \mathrm{~N} / \mathrm{cm} 2$ gives enough pressure to prevent a thin oil layer that present on surface.We also notice that for small $\mathrm{g} / \mathrm{h}$ ratio (the gap of guard and guarded electrode is small compared to the sample) or thick sample, the fringing effect is high. Therefore calculation of effective area according to IEC 60093 is considerably applicable for thick sample. These results could be used as a consideration when measuring dielectric properties of oil immersed pressboardin compliment with IEC 60093 and IEC 60250.
\end{abstract}

Keywords: electrode; permittivity; oil immersed pressboard.

\section{Introduction}

Dielectric properties including relative permittivity, dielectric dissipation factor andd.c.conductivity have been used as design and diagnosticparameters of insulation system conditions for power transformers [1].In order to design a power transformer, the interaction between oil and solid insulation material has to be considered and fully understood.It is known that when measuring dielectric properties of mineral oil and oil immersed pressboard(OIP), there are many factor that might influence the results i.e.live electrode curvature corner shape,contact between electrode and sample, temperature and electric field stress [2]. Further more, recently, researchers have been trying to measure dc resistivity of oil immersed pressboard (OIP) with higher voltage level as to simulate the real system, especially for HVDC [3].

When measuring on high voltage, the effect of electrode's corner ought to be taken into account as the electric field distribution influences the electrical conductivity [4].Therefore, we need to analize the effect of electric field enhancement at the interface of dielectric system (at the contact point or near contact point) to produce a proper measurement result. The electric field enhancementoccur with the addition of solid insulation to the oil insulation system. The configuration will yield an interfaceso called"triple junction". Several publication explained electric field enhancement at the triple junction $[5,6,7,8]$.

Received: March $20^{\text {th }}, 2012$. Accepted: October $28^{\text {th }}, 2012$ 
Other factor that might influence the oil impregnated dielectric properties measurements are pressure of electrode which were performed in an oil bath. Therefore a thin oil layer was always present on surface. This layer could influence results of the measurements of the impregnated pressboard sample was examined [9]. Therefore, the weight of electrode plays an important role to reduce the effect of non-flatness surface of the pressboard which can reduce the measurement accuracy. Unfortunately when measuring dielectric properties according to IEC 60093 and IEC $60250[10,11]$, the shape and weight of electrode are not fully explained.

In this experiment, we have several aims. First, analysing the suitability of electrode corner shape by conducting electric field simulation and laboratory experiment for triple junction configuration. The electric field simulation was done with finite element method using Info lytica Elecnet 7. And then, those results were deepened with partial discharge inception voltage (PDIV) and partial discharge (PD) test, as to verify the effect of electric field enhancement at the triple junction. Second, analysing the effect of electrode's weight on the measurement result by conducting pressure simulation with software Solid works 2010 and then performed permittivity experiments. Third, observing the influence of temperature on the characteristic ofdielectric properties of OIP, observing the influence of different electric field stress on the characteristic ofdielectric properties of OIP. Finally, the experiment could be used as a compliment to IEC and ASTM standards on how to measure dielectric properties of oil immersed pressboard.

\section{D.C. Conductivity\& Permittivity}

As postulated, the field $E(t)$ generates a total current density $j(t)$, which can be written as follows $($ for $\mathrm{E}(\mathrm{t})=$ constant $)$

$$
j(t)=\sigma_{0} E(t)+\varepsilon_{0}\left[\varepsilon_{\infty} \delta(t)+f(t)\right] E(t)
$$

Under step d.c. „,charging voltage“ of magnitude $U_{c}$, the polarization current $\mathrm{i}_{(\mathrm{pol})}$ through the test object is as follows

$$
i_{p o l}(t)=C_{0} U_{c}\left[\frac{\sigma_{0}}{\varepsilon_{0}}+\varepsilon_{\infty} \delta(t)+f(t)\right]
$$

Where $C_{0}$ is the geometric capacitance of test object, $\delta(t)$ is the delta function arising from the application from suddenly applying step voltage. The first part relate to conductivity of the test object. The second part relate to very fast polarization process which cannot be measured. The third part relate to the active polarization process during voltage application[12].Under long time of measurement, the third part of the current are died down. Therefore, the current only relate to conductivity $i_{\text {conductance }}$ of the test object as follows

$$
i_{\text {conductance }}(t)=C_{0} U_{c} \frac{\sigma_{0}}{\varepsilon_{0}}
$$

And the d.c. conductivity can be determined after the steady state current flow as follows [10]:

$$
\sigma_{0}=1 /\left(\frac{U_{c}}{i_{\text {conductance }}} * \frac{A}{h}\right)=1 /\left(R_{x} \cdot \frac{A}{h}\right)
$$

As for permittivity, is determined as follows [11]:

$$
\begin{aligned}
\varepsilon_{r} & =\frac{C_{x}}{C_{0}} \\
C_{0} & =\varepsilon_{0} \cdot \frac{A}{h}
\end{aligned}
$$


Where, $U_{c}, i_{\text {conductance }}$ and $C_{x}$ are the voltage applied, the current conductance and the capacitance of tested OIP, respectively. Meanwhile A and $h$ are the effective area of the electrode system and the OIP thickness.

One of the elements necessary for the calculation of d.c resistivity and permittivityare the effective surface area of the guarded electrode A.The effective area of the guardedelectrode is always larger than its geometrical area due to fringing effect.In IEC 60093, for disk electrode system with guard ring, $\mathrm{A}$ is determined as

$$
A=\frac{\pi}{4}\left(d_{1}+g\right)^{2}
$$

Meanwhile,according to[13],the author explained that, in reality, the edge effect is not so large and the effective margin width is smaller than g/2 (IEC 60093). Therefore, they suggested that the effective area is determined as

$$
A=\frac{\pi}{4}\left(d_{1}+B g\right)^{2}
$$

Factor B depends on the ratio gap width (between guard and guarded electrode) and sample thickness, $g / h$. This B factor could be calculated as

$$
B=1-\frac{4}{\pi} \frac{h}{g} \ln \cosh \left(\frac{\pi}{4} \frac{g}{h}\right)
$$

\section{Remarks for D.C. Conductivity Measurement of OIP}

Until to now, there are no international standards of oil immersed pressboard [3]. According IEC and ASTM standards, the conductivity is measured at predetermined times, i.e. at 1, 2, 5, 10, 50 or $100 \mathrm{~min}$ for IEC 60093 and at $60 \mathrm{~s}$ for IEC 60247, ASTM D257-99 and ASTM D1169-02, as shown in Figure 1[10,14,15,16]. However, the conductivity is measured at predetermined times which sometimes do not comply to the correct value as the polarization current has not reached steady state. The d.c. conductivity measurement basically is a measurement of total current under long time of dc voltage application until all polarization effect in dielectrics died down (transient time), as shown in Figure 1. Therefore, we should determine the d.c. conductivity value when all the polarization effect died down and leaves only the current conductance with equation (4).

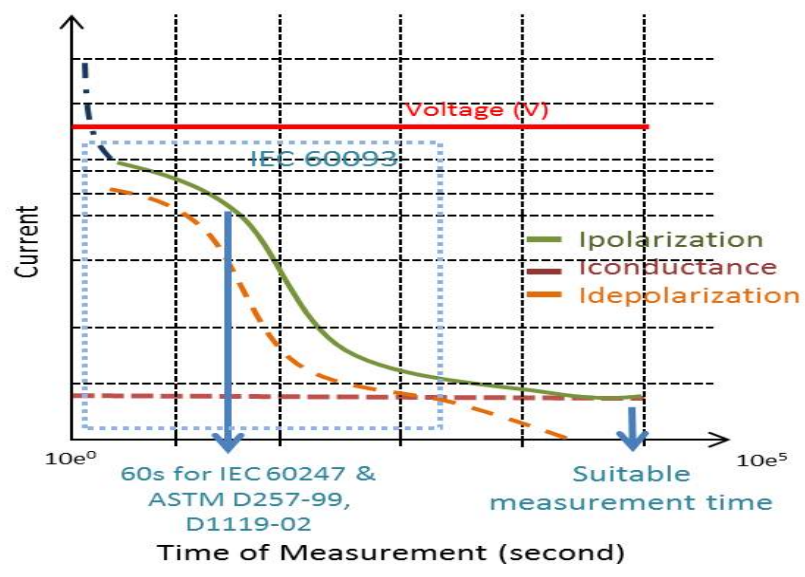

Figure 1. Time of measurement comparison 


\section{Experimental Description}

The experiments were divided into two parts. First, simulation part, where in we carried out electric field simulation with Info lytica Elecnet 7.13 and pressure simulation with Solid works 2010 student edition. Second, laboratory scale experiment, wherein we carried out PD and PDIV investigation and permittivity measurement.

\section{A. PD and PDIV experiment}

Test circuit for PD and PDIV investigation was set up according to IEC 60270[17], as shown in Figure 2. The discharge was measured at the same time with narrowband (Power Diagnostix ICM) and wideband (Oscilloscope Yokogawa DLM series) PD measurement system. With ICM, we recorded the PDIV and PD pattern. Meanwhile with oscilloscope, we recorded the PD pulse current signal and then analysed the frequency domain in PC.

In this experiment, we employed three different live electrodes. The live electrodes used were rounded-cornered with radius $3 \mathrm{~mm}$ and $5 \mathrm{~mm}$ and sharp-cornered electrode (Figure 3). According to IEC 60093, the electrode cornered shape is depicted as sharp cornered. However, in some references, it is normally used rounded cornered electrode as to reduce the electric field enhancement. The purpose of this experiment is to analyse the effect oflive electrode curvature corner shape.

\section{$P D$ and PDIV experimental Procedures}

Until recently, there is no clear definition of PDIV for PD at oil and pressboard interface. Many authors define the PDIV definition $[18,19,20]$ differently.In this experiment, we defined PDIV as the voltage at which the apparent charge of PD was higher than $100 \mathrm{pC}$. Reference [1] mentioned that the cellulose destruction (creeping discharge) beginat apparent charge 100-1000 $\mathrm{pC}$. Therefore at this charge magnitude, PDIV can be used as diagnostic of the beginning of the dangerous charge for insulation.

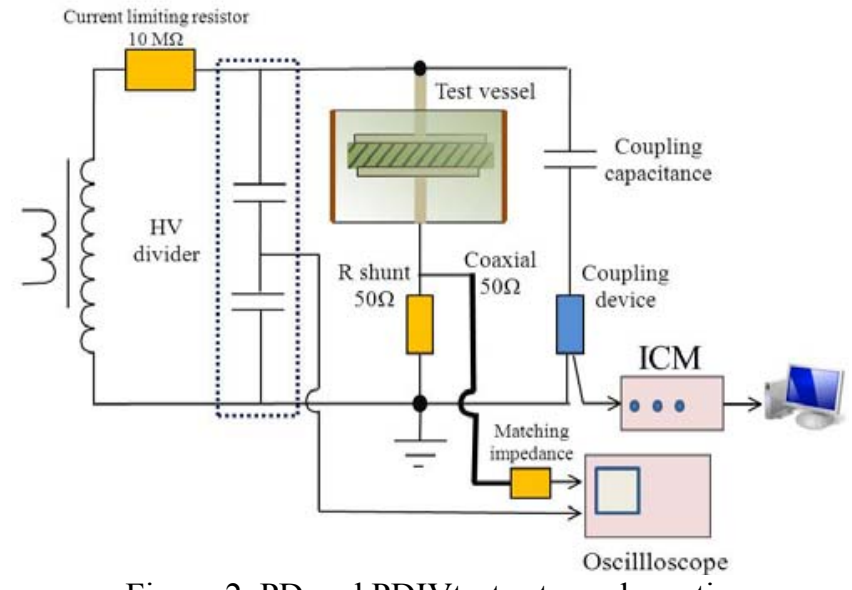

Figure 2. PD and PDIVtest setup schematic
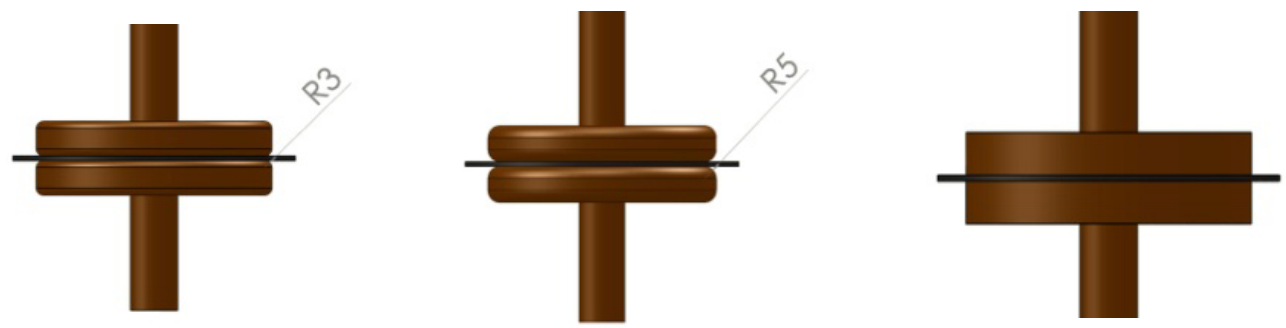

Figure 3. Three types of electrode configuration for PDIV experiment 
In this experiment, the voltage was applied in two consecutive ways [Figure4]:

1. Ramp increased voltage at $1 \mathrm{kV} / \mathrm{s}$ until PDIV $\left(\mathrm{PDIV}_{1}\right)$ was reached [21] [Figure 4a].

2. And then continued measuring with step increased voltage. We began at $80 \%$ of mean PDIV value from the first procedure $\left(\mathrm{PDIV}_{1}\right)$. Then we raised the voltage with step at $1 \mathrm{kV}$ until PDIV $\left(\mathrm{PDIV}_{2}\right)$. After that, we raised the voltage to 1.1 times $\mathrm{PDIV}_{2}$ value and measured the PD pattern and PD pulse current signal at this voltage level for 5 minutes [Figure $4 b]$.

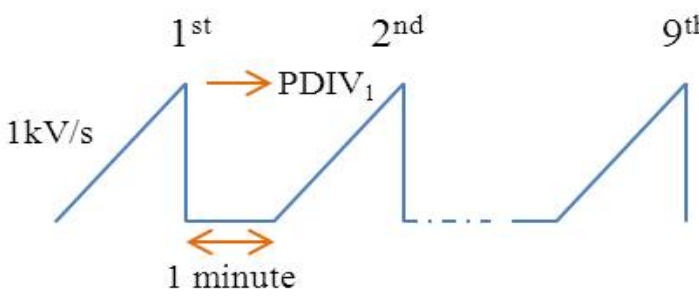

a.

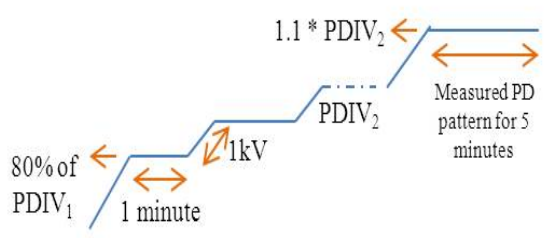

b.

Figure 4. Voltage applied for a. PDIV experiment and b. PD experiment

The first method of voltage appliance was intended to observe the effect of electrode's corner shape on electric field enhancement by means of PDIV. Meanwhile, the second method was intended to measure PD pattern without the risk of breakdown as in this experiment, breakdown occurred easily.

\section{B. Permittivity and dielectric dissipation factor experiment}

In this experiment, we only measured permittivity and dielectric dissipation factor under different conditions i.e. different electric field stress, temperature, and electrode's weight. Test circuit arrangement for measuring permittivity and dissipation factor were set up according to Figure 5a. The capacitance was measured with digital capacitance measuring system, TD SMART from LDIC. The test vessel is vacuum tight and could withstand temperature up to $150^{\circ} \mathrm{C}$ as shown in Figure 5b. It is also equipped with customized micrometer to measure the sample thickness precisely and a heating system. The live electrodes used were disk roundedcornered electrode with radius $3 \mathrm{~mm}$ as it yields uniform electric field at the pressboard side [22] with addition of guard electrode. In this experiments, we varied the pressure of live electrode to analyze the effect of electrode's pressure to reduce the effect of surface roughness of OIP.

\section{Description and preparation of the oil impregnated pressboard and oil}

The Transformer board used were circular $(120 \mathrm{~mm}$ diameter $)$ transformer board type B $3.1 \mathrm{~A}$ with $2 \mathrm{~mm}$ and $4 \mathrm{~mm}$ thickness. The electrical parameters of impregnated pressboard are influenced by the water content, and a high moisture level decreases the electrical and mechanical strength. Therefore before the impregnation, we dried and degassedthe pressboardsfor $72 \mathrm{~h}$ under vacuum (pressure $<1 \mathrm{mbar}$ ) at a temperature of $90^{\circ} \mathrm{C}$.After drying, the samples were impregnated with the insulating liquids under similar conditions and for $72 \mathrm{~h}$ under temperature $90^{\circ} \mathrm{C}$ and vacuum. The moisture content of fully impregnated pressboard samples was below $0.7 \%$.

As for the liquid insulation, we used mineral oil, Nynas Nytro 4000x. The oil was degassed, dried and filtered to the required levels. The water level of the oil was measured at below $5 \mathrm{ppm}$ by a Karl Fischer coulometer. The permittivity of the oil was measured at 2.2 by Baur DTL C. 


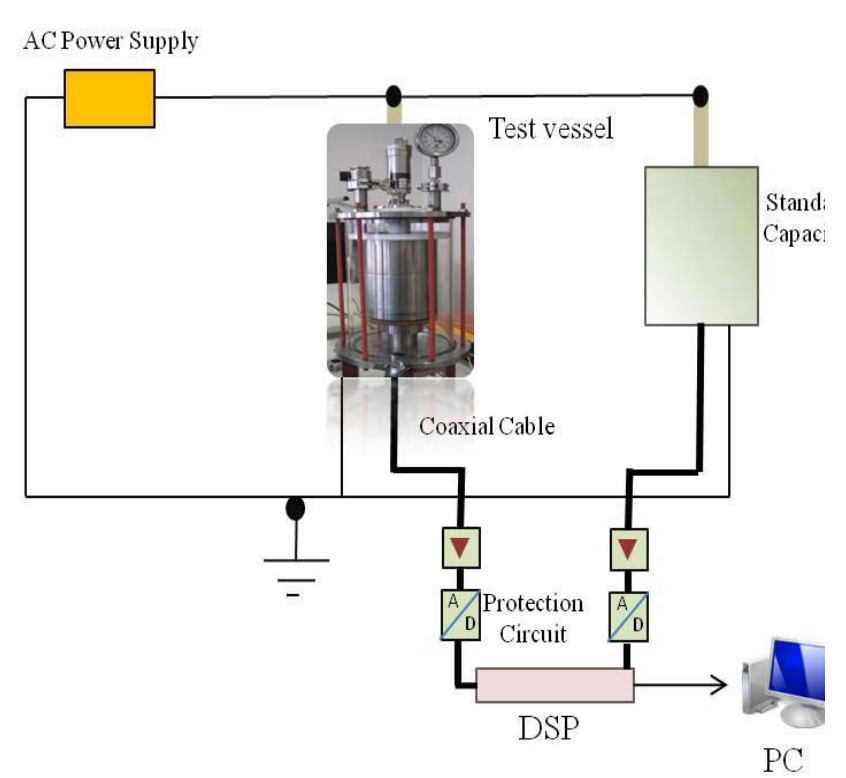

a.

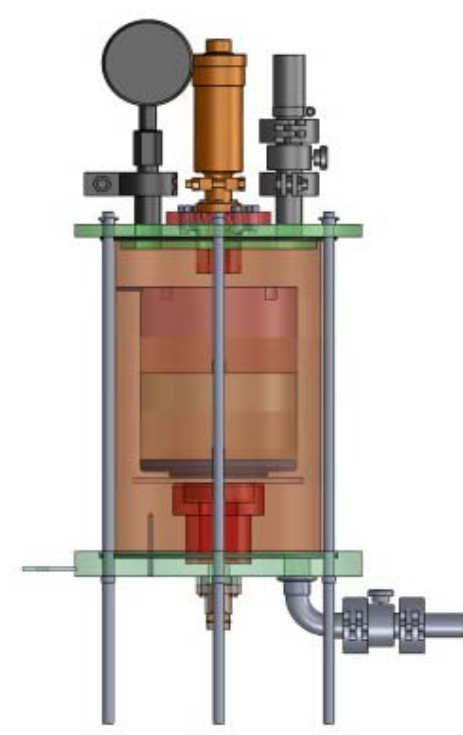

b.

Figure 5a. Permittvity test setup schematic and b. vacuum tight vessel

\section{Results}

\section{A. Simulation results}

As we have explained previously, we carried out two simulations in this work i.e electric field simulation with Infolytica Elecnet 7.13 and pressure simulation with Solid works 2010 student edition.

\section{Electric field simulation}

The relative permittivity of pressboard and oil were kept at 4.3 and 2.2 in all simulations. Therefore the effect of permittivity mismatch is neglected. The electric field enhancements that occur are solely due to the electrode's corner shape at the triple junction.

Figure6a. shows typical electric field magnitude line at pressboard side from the contact point to the edge of the sample (simulated at $1 \mathrm{kV}$ ). The electric field magnitude at the contact point of pressboard side is very high for sharp-cornered electrode compared to roundedcornered electrode. For sharp cornered electrode, there is a steep enhancement at the contact point. Meanwhile, for rounded-cornered electrode, the electric field enhancement is much lower. Round-cornered electrode system generates more uniform field in the pressboard side than sharp-cornered electrode.

Figure $6 \mathrm{~b}$. shows typical the electric field magnitude line at oil side from the contact point to the edge of the sample. The electric field for the round-cornered electrode is very high at the oil side. The enhancement does not occur at the contact point but near the contact point of the triple junction [7]. In reality, this steep enhancement occurs at the oil small gap at the wedge. The maximum electric field for rounded-cornered electrode also occurs at this position. Further more, for $3 \mathrm{~mm}$ and $5 \mathrm{~mm}$ rounded electrode, the field enhancement for $3 \mathrm{~mm}$ electrode is slightly higher. 


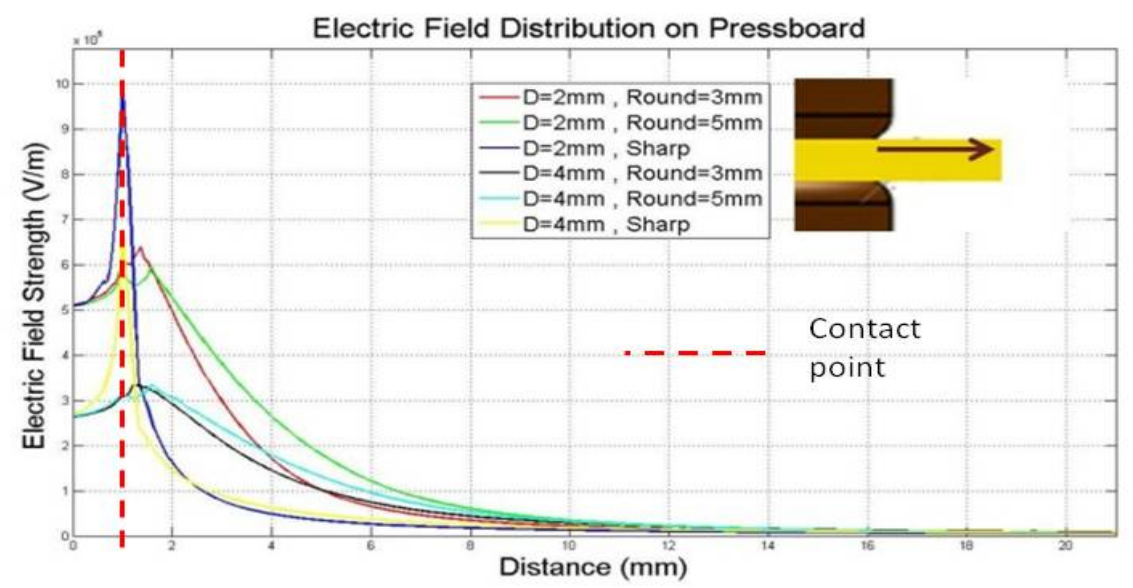

a.

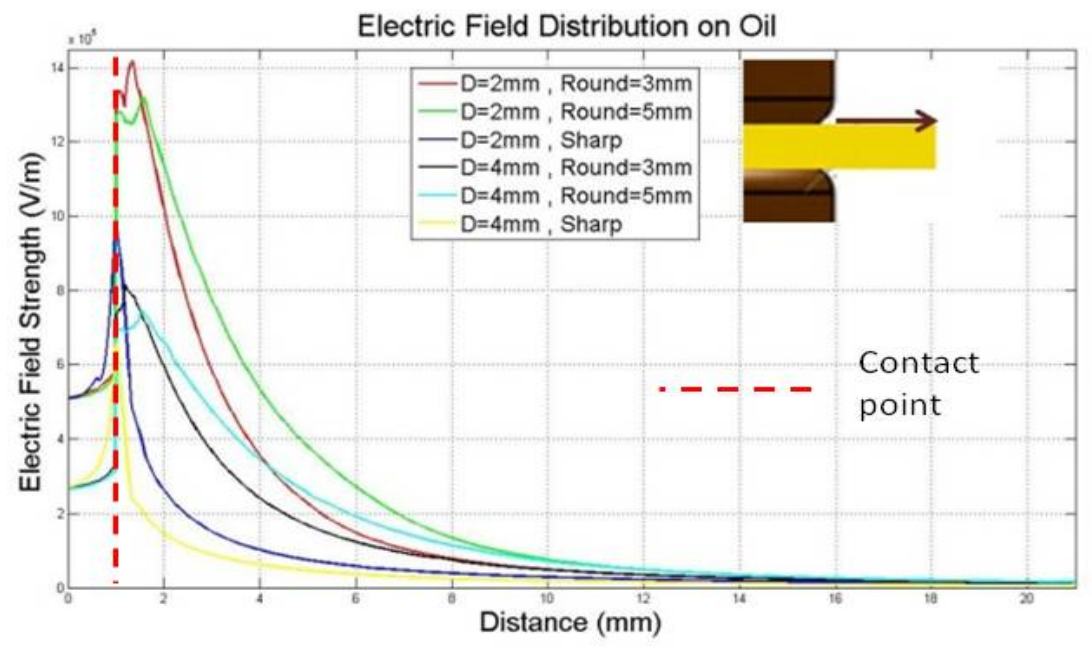

b.

Figure 6. Electric field magnitude distributions from the point of contact a. on pressboard side and $b$. on oil side

\section{Electrode's pressure simulation}

Figure 7 shows the simulated electrode system that we employed in our experiment and pressure distribution on the pressboard surface. The maximum pressure typically occurs at the electrode's corner for both rounded-cornered and sharp-cornered electrode. Meanwhile in the middle of electrode, the pressure distribution is uniform as shown in figure $7 \mathrm{~b}$ (green part on the pressboard). Thus, the pressure distribution behaviour is the similar with electric field stress distribution characteristic which has the highest field enhancement near the contact point. From our simulation, sharp-cornered electrode generate higher pressure on the tip of electrode than rounded-cornered electrode. With this simulation, it is possible to know the highest pressure from electrode. 


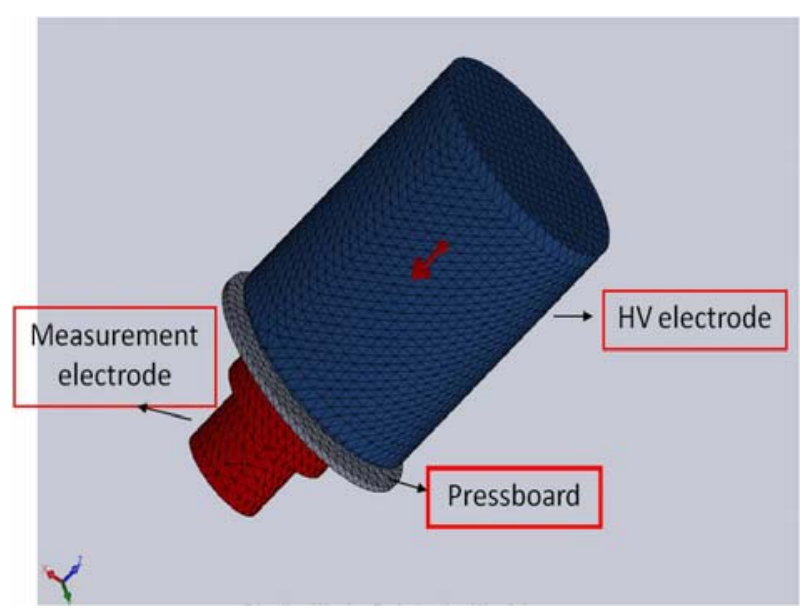

a.

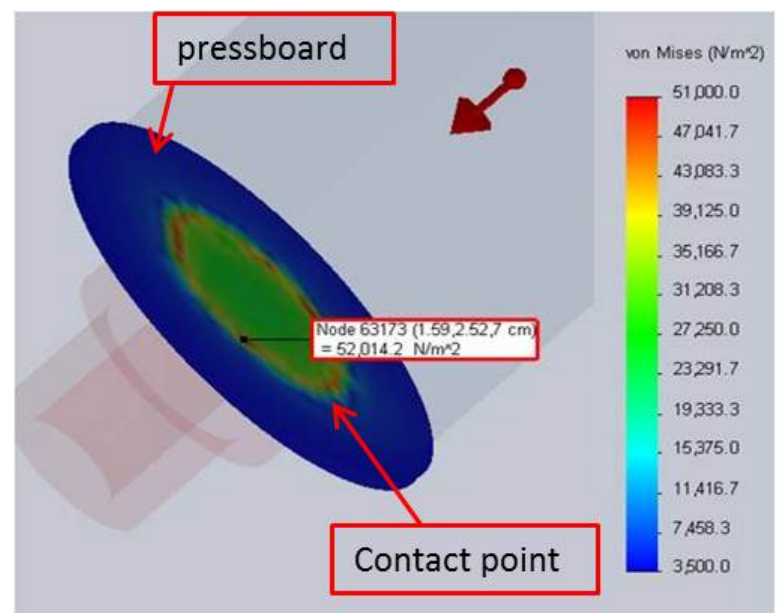

b.

Figure 7a. Electrode system for pressure simulationand b. pressure distribution on pressboard surface

\section{B. $P D$ and PDIV measurement results}

Partial Discharge Inception Voltage (PDIV)

Table 1 illustrated PDIV $_{1}$ values of the each electrode system. It shows that the PDIV value for sharp-cornered electrode is higher than rounded-cornered electrode. This might be attributed to lower electric field enhancement at the oil side near the contact point as shown in Figure $6 \mathrm{~b}$ for sharp-cornered. Meanwhile, for rounded-cornered electrode, lower PDIV value might be attributed to the electric field enhancement at the oil small gap which also the location of the highest electric field. This phenomenon couldpossibly explain that PD in oil/pressboard interface begin in oil as PDIV depends directly on the maximum field [23].

Meanwhile, for $3 \mathrm{~mm}$ and $5 \mathrm{~mm}$ rounded electrode, practically, there is no difference in terms of PDIV mean value especially at $2 \mathrm{~mm}$ pressboard. This results confirm the enhancement characteristic at the oil small gap of rounded-cornered electrode as shown in electric field simulation. 
Table 1. The Mean Value of PDIV ${ }_{1}$ of Each Electrode System

\begin{tabular}{|c|c|c|c|}
\hline \multirow{2}{*}{$\begin{array}{c}\text { Sample } \\
\text { thickness }\end{array}$} & \multirow{2}{*}{ Electrode } & \multicolumn{2}{|c|}{ PDIV } \\
\cline { 2 - 4 } & & $\mathbf{U}_{\text {PDIV }}(\mathbf{k V )}$ & $\boldsymbol{\sigma}(\mathbf{k V )}$ \\
\hline \multirow{3}{*}{$2 \mathrm{~mm}$} & Rounded 3mm & 31.85 & 1.3 \\
\cline { 2 - 4 } & Rounded $5 \mathrm{~mm}$ & 32.01 & 1.6 \\
\cline { 2 - 4 } & Sharp & 34.8556 & 1.4 \\
\hline \multirow{3}{*}{$4 \mathrm{~mm}$} & Rounded 3mm & 44.725 & 1.9 \\
\cline { 2 - 4 } & Rounded 5mm & 46.24 & 1.5 \\
\cline { 2 - 4 } & Sharp & $>48$ & - \\
\hline
\end{tabular}

$P D$ pattern and $P D$ pulse current signal analysis

Table 2. Comparison of PD Characteristics

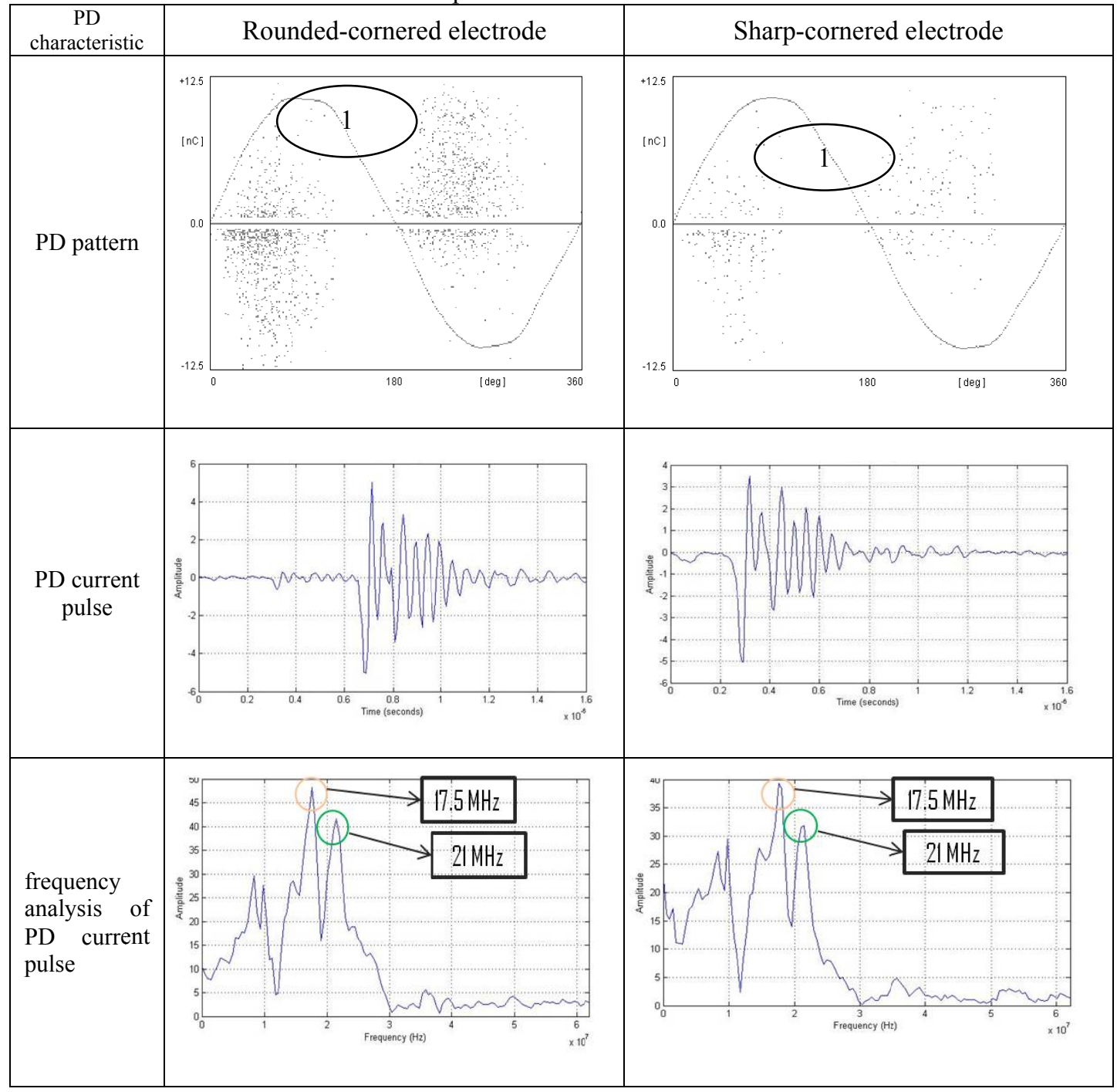


Table 2 illustrated the comparison of typical PD pattern and PD pulse current signal for rounded-cornered electrode and sharp-cornered electrode. PD patterns for both electrodes are similar. Those scattered discharge patterns (ellipse in table 2) indicate the nature of surface discharge that generated at the electrode border [18,24]. References $[19,20]$ also mentioned that surface discharge with this electrode system is similar to the corona in oil. It produces surface discharge that predominantly occur at the oil side.

Meanwhile, from the frequency domain analysis of PD pulse current signal, we showed that PD signals from both electrodes have the same dominant frequency at $17.5 \mathrm{MHz}$. This means that the same discharge mechanism occur with both electrode systems applied.From PD pattern and PD pulse current signal analysis there no indication that internal PD occured at this voltage level or with this electrode system.

\section{Permittivity and dielectric dissipation factor results}

Temperature and Electric Field Stress

Table 3 shows the relative permittivity and dielectric dissipation factor at different temperature. The relative permitivitty and dielectric dissipation factor are sensitive to temperature changing[25]. For pressboards impregnated under mineral oil, the relative permittivity (capacitance) value increases with the increasing temperature. The dielectric dissipation factor increases with the increasing temperature but the change are not significant from $25^{\circ} \mathrm{C}$ ot $60^{\circ} \mathrm{C}$ for pressboard.

The change of dielectric disspation factor are significant at temperature $\geq 90{ }^{\circ} \mathrm{C}$. The change of dissipation factor from temperature $130^{\circ} \mathrm{C}$ to $90^{\circ} \mathrm{C}$ (Figure $8 \mathrm{a}$ ) and from $90^{\circ} \mathrm{C}$ to $60^{\circ} \mathrm{C}$ are presented (Figure $8 \mathrm{~b}$ ). At, $130^{\circ} \mathrm{C}$ the dissipation factor reach $4.5 \%$, meanwhile at $90^{\circ} \mathrm{C}$ is $0.7 \%$. The change of dissipation factor at higher temperature is significant compare to the change at temperature from $25^{\circ} \mathrm{C}$ to $90^{\circ} \mathrm{C}$.

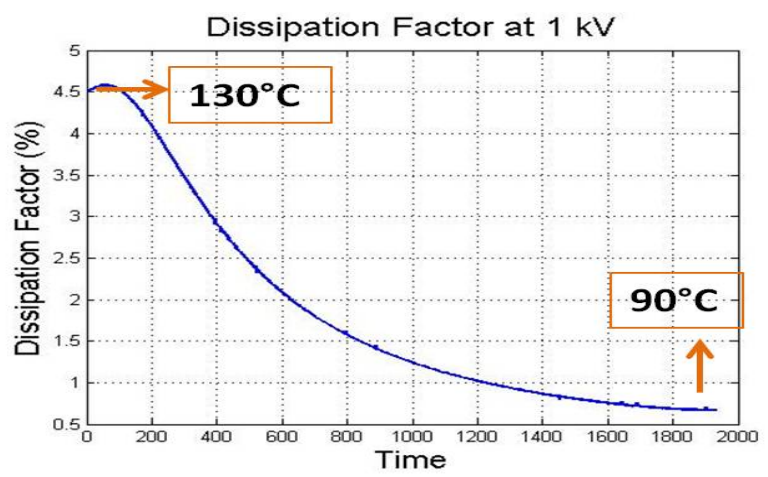

a.

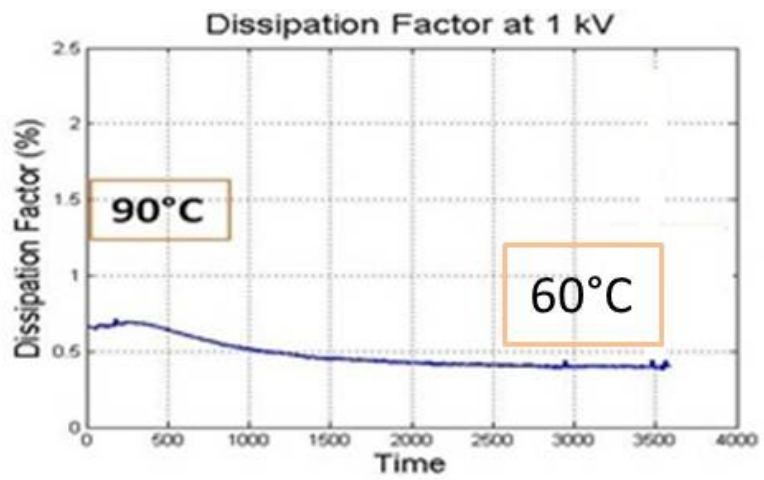

b.

Figure 8. Dissipation factor for changing of temperature a. from $130^{\circ} \mathrm{C}$ to $90{ }^{\circ} \mathrm{C}$ and b. from $90^{\circ} \mathrm{C}$ to $60^{\circ} \mathrm{C}$ 
We also compared the relative permittivity calculated with different effective area (A) equation (equation 7 and 8). The $\mathrm{B}$ factor in equation 8 is about 0.83 [13] for $g / h$ ratio 0.5 (1 $\mathrm{mm}$ gap and $2 \mathrm{~mm}$ pressboard). Table 3 shows the relative permittivity values are relatively the same for both equations.It means that for small $g / h$ ratio (the gap is small compared to the sample) or thick sample, the fringíng effect is high. Therefore the equation 7 from IEC 60093 is considerably applicable for thick sample.

Table 3. Relative Permittivity and DDF VS Temperature

\begin{tabular}{|c|c|c|c|c|c|}
\hline \multirow[b]{2}{*}{ No } & \multirow[b]{2}{*}{ Voltage $(\mathrm{kV})$} & \multirow[b]{2}{*}{$\operatorname{Temp}\left({ }^{\circ} \mathrm{C}\right)$} & \multicolumn{2}{|c|}{$\varepsilon_{\mathrm{r}}$} & \multirow[b]{2}{*}{$\operatorname{DDF}(\%)$} \\
\hline & & & Eq. 6 & Eq. 7 & \\
\hline 1 & \multirow{4}{*}{1} & 20 & 4.39 & 4.42 & 0.4 \\
\hline 2 & & 60 & 4.54 & 4.57 & 0.4 \\
\hline 3 & & 90 & 4.63 & 4.66 & 0.7 \\
\hline 4 & & 130 & - & - & 4.5 \\
\hline
\end{tabular}

As for the effect of electric field stress for measuring permittivity and DDF is shown in Figure 9. The relative permittivity of pressboards do not depend on voltage applied for voltage range $250 \mathrm{~V}-10 \mathrm{kV}$ (Electric field stress $0.125 \mathrm{kV} / \mathrm{mm}-5 \mathrm{kV} / \mathrm{mm}$ ). It seems from the preliminary measurement, the dielectric dissipation factor of pressboards also do not depend on voltage applied at voltage range $250 \mathrm{~V}-10 \mathrm{kV}$. Similar results are shown in [26].

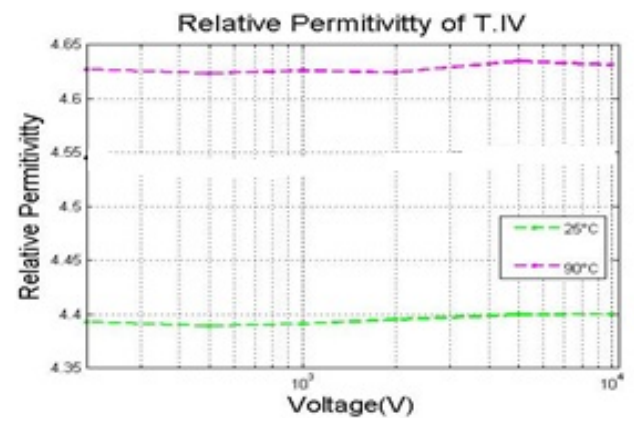

a.

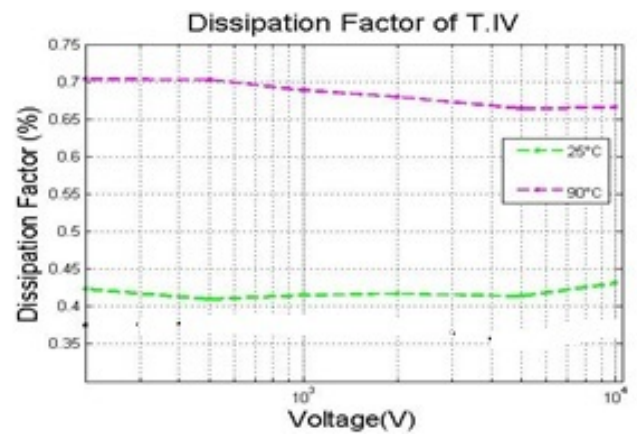

b.

Figure 9. a. relative permittivity and b. dissipation factor of OIP for applied voltage $250 \mathrm{~V}-10 \mathrm{kV}$. 


\section{Pressure of Electrode}

In this experiments, we varied the pressure of live electrode to analyze the effect of electrode's pressure to reduce the effect of surface roughness of OIP as illustrated in Table 4. It shows that low pressure electrode as low as, $0.36 \mathrm{~N} / \mathrm{cm}^{2}$, is not enough to prevent a thin oil layer that present on surface which could influence the result of the measurements. For electrode with pressure higher than $1.91 \mathrm{~N} / \mathrm{cm}^{2}$, the capacitance measured (therefore relative permittivity) were almost the similar.However, we have to take notice that too much pressure (from one massive electrode), usually, do not properly adhere to stiff dielectrics and may cause measuring errors [27].

Table 4. Correlation Between Electrode's Pressure \& Permittivity

\begin{tabular}{|c|c|c|c|c|}
\hline \multirow{2}{*}{$\begin{array}{c}\text { Electrode } \\
\text { system }\end{array}$} & \multicolumn{2}{|c|}{ Pressure } & \multicolumn{2}{c|}{$\varepsilon_{R}$} \\
\cline { 2 - 5 } & $\begin{array}{c}\text { Max } \\
\text { corner of } \\
\text { electrode) }\end{array}$ & Mean & Mean & $\sigma$ \\
\hline $\mathrm{A}$ & $1.4 \mathrm{~N} / \mathrm{cm}^{2}$ & $0.36 \mathrm{~N} / \mathrm{cm}^{2}$ & 4.14 & 0.064 \\
\hline $\mathrm{B}$ & $3.03 \mathrm{~N} / \mathrm{cm}^{2}$ & $1.91 \mathrm{~N} / \mathrm{cm}^{2}$ & 4.25 & 0.067 \\
\hline $\mathrm{C}$ & $5.05 \mathrm{~N} / \mathrm{cm}^{2}$ & $3.3 \mathrm{~N} / \mathrm{cm}^{2}$ & 4.26 & 0.065 \\
\hline
\end{tabular}

\section{Conclusion and Discussion}

The shape of electrode's corner affect the electric field distribution at the triple junction interface of oil immersed pressboard as shown by electric field simulation and experiments, PDIV and PD pattern. Lower PDIV mean values were observed for round-cornered electrode, which means that the field intensification at the wedge of round-cornered electrode is higher compared to sharp-cornered. This is verified by electric field simulation that shows the electric field enhancement at the oil side is lower for sharp-cornered electrode.

From pressboard with thickness, 2 and $4 \mathrm{~mm}$, we found that thicker pressboard has higher PDIV level. This means that electric field enhancement at triple junction also depend on the thickness of the sample.

Meanwhile, PD pattern and PD pulse current signal analysis shows that the same discharge phenomenon occur for sharp-cornered electrode and round-cornered electrode. The discharge phenomenon begins with discharge in small oil gap. And then, it evolves to be surface discharge which is verified by the PD pattern $[24,28]$. It can be said that surface strength of pressboard depend on the oil discharge. Furthermore, the oil discharge in the interface depend on the electric field enhancement, one of which caused by electrode's corner shape.

Eventhough round-cornered electrode yields more uniform electric field at the pressboard side, it also yields steep electric field enhancement at the oil side. This nature of roundedcorner electrode makes it easier to generate discharge in oil at the wedge when compared to sharp-cornered electrode [29]. For measuring dielectric properties at high voltage level, this phenomena should take into account, as dielectric dissipation of insulation is also caused by interface polarization and partial discharges [26]. Meanwhile, for the sharp cornered electrode, the highest electric field enhancement occurred at the pressboard side. Therefore the electric field distribution is not uniform in pressboard. It might affect the measurement of dielectric properties because we measure very low current. However, the extent of these two phenomena on the measurement results of dielectric properties should be proven.

Pressure of electrode plays an important role to overcome the effect of non-flatness of pressboard surface. It was found that electrode with pressure higher than $1.9 \mathrm{~N} / \mathrm{cm} 2$ give enough pressure to prevent a thin oil layer that present on surface which influenced the measurement results.

The relative permitivitty of pressboards increases with the increase of temperature. The dielectric dissipation factor of oil immersed pressboard increases with the increase of temperature. The change is significant only for temperature $\geq 90^{\circ} \mathrm{C}$. Meanwhile, the relative 
permitivitty and dielectric dissipation factor of pressboard do not depend on the electric field stress. Which means measuring at relatively low voltage will give advantage since it will give the same results.

By comparing permittivity value calculated using 2 equations, we notice that for small $\mathrm{g} / \mathrm{h}$ ratio (the gap is small compared to the sample) or thick sample, the fringíng effect is high. Therefore the effective area calculation from IEC 60093 is considerably applicable for thick sample.

These results could be used as a consideration on which electrode is suitable for measuring dielectric properties of pressboard immersed in oil in compliment with IEC standards.

\section{Acknowledgment}

The authors would like to express their thanks toRiza Yukananto B.Eng from Twente University, Netherland for the pressure simulation.

\section{References}

[1] V. Sokolov, Z. Berler, and V. Rashkes, "Effecctive Methods of Assesment of Insulation System Conditions in Power Transformer: A View Based on Practical Experience," Proceedingsof Electrical Insulation Conference and Electrical Manufacturing \& Coil Winding Conference, 1999.

[2] Küchler, F. Huellmandel, K. Boehm, M. Liebschner, C. Krause and B. Heinrich, "Parameter Determining the Dielectric Properties of Oil Impregnated Pressboard and Presspaper in AC and DC Power Transformer Application" ISH 07 International Symposium on High Voltage Engineering, 2007.

[3] Küchler, M. Liebschner, A. Reumann, C. Krause, U. Piovan, B. Heinrich, R. Fritsche, J. Hoppe, A. Langens and J. Titze, " Evaluation of Conductivities and Dielectric Properties for Highly Stressed HVDC Insulating Material" CIGRE Session 2010, Paper D1_106_2010, 2010.

[4] T. Judendorfer, A.Pirker, and M. Muhr, "Conductivity Measurements of electrical insulating oil," IEEE International Conference on Dielectric Liquid, 2011.

[5] T. Takuma and T. Kawamoto, "Field Intensification Near Various Points of Contact with A Zero Contact Angle Between A Solid Dielectric and an Electrode," IEEE Transaction on Power Apparatus and System, vol. PAS-103, No. 9, September 1984.

[6] T. Takuma, "Field Behaviour at a Triple Junction in Composite Dielectric Arrangement," IEEE Trans. on Electrical Insulation, vol. 26, No. 3, June 1991.

[7] L. Schächter, "Analytic expression for triple-point electron emission from an ideal edge," Journal of Applied Physics, vol. 72, No. 4, 26 January 1998.

[8] M.S. Chung, T.S. Choi and B.G. Yoon, "Theoritical analysis of the field enchancement in a two dimensional triple junction," Applied Surface Science, vol. 251, Issues 1-4, 15 September 2005.

[9] Ekanayake, S. Gubanski, A. Graczkowski and K. Walczak, "Frequency Response of Oil Impregnated Pressboard and Paper Samples for Estimating Moisture in Transformer Insulation," IEEE Transaction on Power Delivery, Vol. 21, No.3, July 2009.

[10] IEC60093, "Methods of test for volume resistivity and surface resistivity of solid electrical insulating materials," 1980.

[11] IEC60250," Recommended methods for the determination of the permittivity and dielectric dissipation factor of Electrical insulating material at power, audio, and radio frequencies including metre wavelengths," 1969.

[12] W.S. Zaengl,'Dielectric Spectroscopy in Time Domain and Frequency Domain for HV Power Equipment, Part I: Theoritical Consideration," IEEE ElectricalInsulation Magazine,Vol.19, No. 5, September/October 2003. 
[13] M. Lisowski and R. Kacprzyk, "Changes Proposed for the IEC 60093 Standard Concerning Measurements of the Volume and Surface Resistivities of Electrical Insulating Materials," IEEE Transaction on Dielectrics and Electrical Insulation, Vol. 13, No.1, February2006.

[14] IEC60247, "Insulating liquids - Measurement of relative permittivity, dielectric dissipation factor $(\tan \delta)$ and d.c. resistivity," 2004-2.

[15] ASTM D 257, "Standard Test Methods for DC Resistance or Conductance of Insulating Materials1," 1999.

[16] ASTM D 1169, "Standard Test Method forSpecific Resistance (Resistivity) of Electrical InsulatingLiquids," 2002.

[17] IEC 60270, "High voltage test technique - Partial discharge measurements," 2000.

[18] G. Berg and L.Lundgaard, "PD signatures of wedge type discharges in transformer insulation," Proceeding of $14^{\text {th }}$ International Conference on Dielectric Liquids, Graz, Austria, 2002.

[19] J. Li, W. Si, X. Yao and Y. Li, "Partial Discharge Characteristics over Differently Aged Oil/Pressboard Interfaces," IEEE Trans. On Dielectrics and Electrical Insulation, vol. 16, No. 6, December 2009.

[20] J. Dai, Z.D. Wang, and P. Jarman "Creepage Discharge on Insulation Barriers in Aged Power Transformers," IEEE Trans. On Dielectrics and Electrical Insulation, vol. 17, No. 4, August 2010.

[21] IEC/TR 61294 ed, 1.0, "Insulating liquids - Determination of the partial discharge inception voltage (PDIV) - Test procedure," 1993.

[22] F. Pratomosiwi, N. Pattanadech, B. Wieser, G. Pukel, M. Stössl, and M. Muhr, "The Study of Electrode Corner Shape forMeasuringDielectric Properties of Oil Immersed Material", International Conference on High Voltage Engineering and Application, ICHVE 2012.

[23] N. Pattanadeh, F.Pratomosiwi, B, Wieser, M. Baur and M.Muhr,"The Study of Partial Discharge Inception Voltage of Mineral Oil Using Needle - Plane Electrode Configuration”, International Conference on High Voltage Engineering and Application, ICHVE 2012.

[24] A. Cavallini, G.C. Montanari, B.Codet and P. Vetu, "Condition Assessment of Instrument Transformer by Partial Discharge Analysis: a Comprehensive Approach," IEEE International Conference on Dielectric Liquid, 2005.

[25] T. Prevost, "Dielectric Properties of Natural Esters and their Influence on Transformer Insulation System Design and Performance" IEEE PES Transmission and Distribution Conference and Exhibition 2006.

[26] M. Farahani, H. Borsi, and E: Gockenbach, "Experience with partial discharge, dissipation factor, and recovery voltage measurements for the evaluation of insulation system of high votlage rotating machine,"Annual Report Conference on Electrical Insulation and Dielectric Phenomena, 2002.

[27] M. Lisowski and R. Kacprzyk, "Effective Area of Thin Guarded Electrodein Determining of Permittivity and Volume Resistivity," IEEE Transaction on Dielectrics and Electrical Insulation, Vol. 16, No.1, February2009.

[28] G. Bergand L.Lundgaard, "Discharges in combined transformer oil/paper insulation," Proceding of the twenty-first symposium on electrical insulating material, 1999.

[29] H. Tsukioka, E. Ohe, Y. Kamata, M. Mejima, M. Nozaki and K. Hyodo, "Development of Low Dielectric Constant Pressboard," Proceding of the twenty-first symposium on electrical insulating material, 1988. 


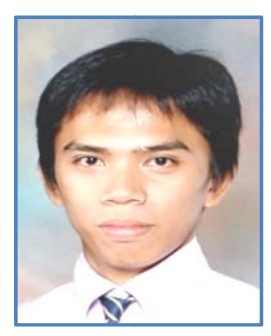

Fari Pratomosiwi was born in Indonesia in 1985. He received B.Eng. and M.Eng. degrees in electrical engineering from Bandung Institute of Technology (ITB), Indonesia in 2007 and 2009, respectively. Now he is currently PhD student in the Institute of High Voltage Engineering and System Management, Graz University of Technology, Austria. His major research interests are high voltage insulating materials for substitutes of insulating mineral oils and partial discharge.

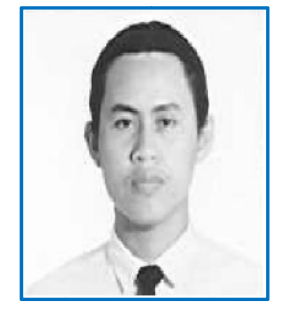

Norasage Pattanadech received B.Eng and M.Eng degree in electrical engineering from King Mongkut's Institute of Technology Ladkrabang (KMITL) in 1997 and Chulalongkom University in 2001 respectively. He joined Mahanakom University of Technology in 2001 - 2003 before working in King Mongkut Institute of Technology Ladkrabang, Bangkok, Thailand until now. He is now also studying for Ph.d. in the Institute of High Voltage Engineering and System Management, Graz University of Technology, Austria. His research activities have been mainly involved Partial discharge in insulating liquid, solid insulator charactoristics, high voltage testing and equipment, and Electromagnetic Compatibility.

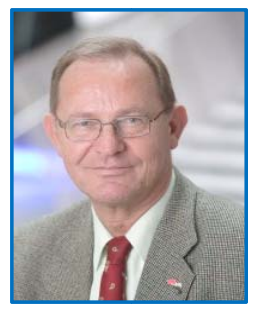

Michael Muhr is an emeritus professor at the High Voltage Engineering and System Management of Graz University of Technology (TU Graz), Austria. Since 1990, he has been the Head of the Institute and Test Institute of High Voltage Engineering and System Management of TU Graz. He is a member ÖVE, ÖGE, DKE, IEEE, IEC and CIGRE (convenor of 5 working groups). He has published more than 170 publications and reports and also more than 160 lectures. He received Honorary Doctoral „Dr.h.c.“ from the West Bohemian University of Plzen. 